Article

\title{
Investigation of the Tribological Performance of Heterogeneous Slip/No-Slip Journal Bearing Considering Thermo-Hydrodynamic Effects
}

\author{
Mohammad Tauviqirrahman ${ }^{1, *}$, M. Fadhli Afif ${ }^{1}$, P. Paryanto ${ }^{1,2}$, J. Jamari ${ }^{1}\left(\mathbb{D}\right.$ and Wahyu Caesarendra ${ }^{3}(1)$ \\ 1 Laboratory for Engineering Design and Tribology, Department of Mechanical Engineering, \\ Faculty of Engineering, Diponegoro University, Jl. Prof. Soedharto SH, Tembalang, \\ Semarang 50275, Indonesia; fadhliafifm@gmail.com (M.F.A.); paryanto@gmail.com (P.P.); \\ j.jamari@gmail.com (J.J.) \\ 2 Institute for Factory Automation and Production Systems (FAPS), Friedrich-Alexander-Universität \\ Erlangen-Nürnberg, Egerlandstr. 7-9, 91058 Erlangen, Germany \\ 3 Faculty of Integrated Technologies, Universiti Brunei Darussalam, Bandar Seri Begawan BE1410, Brunei; \\ wahyu.caesarendra@ubd.edu.bn \\ * Correspondence: mohammad.tauviqirrahman@ft.undip.ac.id
}

Citation: Tauviqirrahman, M.; Afif, M.F.; Paryanto, P.; Jamari, J.; Caesarendra, W. Investigation of the Tribological Performance of Heterogeneous Slip/No-Slip Journal Bearing Considering Thermo-

Hydrodynamic Effects. Fluids 2021, 6 , 48. https://doi.org/10.3390/fluids6 020048

Received: 14 December 2020

Accepted: 14 January 2021

Published: 21 January 2021

Publisher's Note: MDPI stays neutral with regard to jurisdictional claims in published maps and institutional affiliations.

Copyright: (C) 2021 by the authors Licensee MDPI, Basel, Switzerland. This article is an open access article distributed under the terms and conditions of the Creative Commons Attribution (CC BY) license (https:// creativecommons.org/licenses/by/ $4.0 /)$

\begin{abstract}
The slip boundary has an important influence on hydrodynamic journal bearing. However, less attention has been paid to the positive effect of slip on thermal behaviour. In this study, a computational fluid dynamics (CFD) analysis investigating the thermo-hydrodynamic (THD) characteristics of heterogeneous slip/no-slip bearings running under steady, incompressible, and turbulent conditions is presented. A comprehensive analysis is made to investigate the THD behaviours of heterogeneous slip/no-slip bearings in terms of lubricant pressure, temperature distribution, volume fraction of vapor, and load-carrying capacity when they are running under different shaft rotational speeds. The multiphase cavitation model is adopted to represent the real operational condition of the journal bearing. Numerical results show that the load-carrying capacity of the heterogeneous slip/no-slip bearing can be significantly increased by up to $100 \%$ depending on the rotational speed. It is also observed that there is an optimal journal rotational speed for maximizing the load-carrying capacity. An insightful new finding is revealed in a numerical framework, wherein it is found that by introducing the heterogeneous slip/no-slip pattern, the maximum temperature can be reduced by up to $25 \%$ in comparison with a conventional bearing.
\end{abstract}

Keywords: cavitation; computational fluid dynamics (CFD); journal bearing; slip; thermo-hydrodynamic lubrication

\section{Introduction}

In most friction pairs, attention has been paid to the use of the (super)hydrophobic coating in enhancing the tribological performance and prolong the lifetime of a bearing. Early studies showed that such a coating could induce wall slip due to its non-stick property [1-7]. Nowadays, a deterministic hydrophobic coating was introduced deliberately on the bearings by engineering the surface. An engineered slip/no-slip pattern, in which slip exhibits in specific zones and is absent in others, is claiming progressively more attention in enhancing the load support and lowering the friction force of the bearing.

Many works have been performed exploring the benefits of heterogeneous slip/noslip of hydrodynamic journal bearings. It is worth mentioning the early work of Fortier and Salant [8], who examined the effect of heterogeneous slip/no-slip pattern by performing numerical studies on load support, side leakage, and the friction force. On a different path, Kalavathi et al. [9] examined the performance of heterogeneous slip/no-slip journal bearing considering surface roughness. Moreover, the optimized slip parameters have been shown to dramatically enhance the performance characteristics of the bearings, specifically 
in increasing the bearing stability performance $[10,11]$ and in suppressing the occurrence of cavitation [12]. Related studies revealed even that in some conditions, a concentric journal bearing exhibits better tribological characteristics than a heterogeneous slip/no-slip slip journal bearing at higher eccentricity ratios optimized for different working conditions [13-16]. This indicates that the geometrical wedge effect is not the only mechanism in lifting the pressure generation of the slip journal bearing.

Attempts were performed in several studies to explore the optimal shape and location of the slip zone that would maximize the load support (equivalent to maximizing the fluid film thickness) or minimize friction. This is because, in some cases, inappropriate slip parameters application on the surface can be harmful to the bearing performance $[12,13,17]$. Therefore, particular care must be taken in choosing the slip zone geometry. On a high-speed hybrid journal bearing, Lin et al. [18] showed that the improved tribological performance could be achieved by a well-designed partial slip surface, especially if the slip surface is placed near the bearing center in the axial direction. Similarly, in recent lubrication, Cui et al. [17] performed optimization of the zone slip parameters under moderate and high eccentricity ratios for a high-speed journal bearing. They suggested that, to obtain enhanced performance of journal bearings, the slip boundary in the axial direction should be enlarged by setting the slip zone to be the maximum rectangular, while, in the circumferential direction, the optimal zone is set at the convergent region. Many studies have also been conducted to compare the influence of slip condition with the effect of surface texturing under similar lubrication situations [18,19]. Their investigations highlighted that the tribological performance of the textured surface was identical to that of the slip surface. A similar conclusion has also been revealed by Bhattacharya et al. [11]. The authors reported that the pressure profile trend with multiple slip-no-slip zones is similar to that obtained for multilobe bearings. Further, by assessing the positive effects of surface texturing and wall slip, many researchers have conducted numerical studies to investigate the combined effect of slip and surface texturing on hydrodynamic journal bearings. Using the critical shear stress model in modelling the wall slip, Aurelian et al. [19] pointed out that a journal bearing with combined slip-texture zone improves load support and decreases power loss. Lin et al. [20] demonstrated that the zone and location of the textured/slip surface would significantly affect the load support. Later, Susilowati et al. [21] revealed that the combined techniques of texture and slip have a significant influence on the enhancement of the tribological performance of a bearing. Subsequently, Rao et al. [15,22-24] have investigated the beneficial effects and potential of partial slip-texture on the enhancement of the load support, the friction coefficient and the stability of the bearing, either Newtonian or Non-Newtonian lubricated. The same authors also showed that heterogeneous slip/no-slip pattern is superior to textured-slip pattern in terms of the load support and friction coefficient in the case of micro-polar and power-law fluid lubricated journal bearings [22] and the case of magnetohydrodynamic lubrication [24]. In these studies, however, the non-mass conserving cavitation algorithm has been employed and the results were questionable, as first investigated by Ausas et al. [25]. In the journal bearing, alternating converging and diverging film areas made the pressure vary between the cavitated and lubricated regions. Cavitation occurs when the lubricant pressure is less than the vapor pressure in the divergent zone of the bearing. It produces a two-phase condition and creates gas bubbles. The generation mechanism of the vapor cannot be analyzed by the conventional methods, such as Reynolds boundary condition, which were often adopted by researchers. Consequently, the transition between liquid and vapor could not be investigated, and the cavitation region not be satisfactorily predicted.

As is commonly known, a variety of cavitation models such as the half-Sommerfeld model, the Reynolds boundary condition, the Rayleigh-Plesset equation, and the JakobssonFloberg-Olsson (JFO)-type cavitation models have been built to predict the occurrence of the cavitation phenomenon. Among these models, the most common approach to modelling the rupture phenomena is based on the Reynolds cavitation boundary condition. 
Besides, for more complex bearing simulations, a vaporous and gaseous cavitation model have been developed. In these models, the air solubility and dissolution effect in the bearing lubricant have been taken into account. The cavitation effects are essential, causing sudden changes to the bearing performance. Therefore, to predict precisely the cavitation phenomena, it is necessary to employ an accurate cavitation model to avoid the wrong conclusion. Based on experimental [26-29], the pressure on the cavitation area contains vapor-liquid two-phase flows. Currently, Dandhe and Pande [30] have shown that the computational results based on multiphase flow analysis are in good agreement with the experimental data. Another interesting result was shown by Sun et al. [31]. When the results of the single-phase and two-phase flow analysis were compared, the authors revealed that hydrodynamic pressures have a similar feature in the convergent wedge zone but are different in the divergent part of the gap. A lower maximum pressure was observed when the multiphase flow approach was implemented. This finding was strengthened by Chen et al. [32]. To the best of our knowledge, studies on the investigation of the heterogeneous slip/no-slip journal bearing based on multiphase flow analysis for modelling the cavitation are very limited. Therefore, more attempts are required in the area of heterogeneous slip/no-slip journal bearings to provide a needful guide for the design process.

An accurate study and representation of heterogeneous slip/no-slip bearings require detailed modelling. However, the vast majority of the numerical studies on the performance of such bearings are based on the assumption of an isothermal lubricant condition. Such an assumption contradicts a recent study that revealed that the viscosity wedge effect due to temperature difference across the film thickness has a strong role in increasing the load support [33]. This makes the thermal boundary condition important to consider in the analysis of hydrodynamically lubricated contact. As pointed out by Cui et al. [34], there was a relationship between the thermal boundary conditions and viscosity wedge. As the viscosity of the lubricant strongly depends on the temperature, recently thermohydrodynamic analysis of the lubricated contact has gained substantial attention.

Based on an in-depth literature survey, most existing simulation tools for the heterogeneous slip/no-slip journal bearing are questionable for examining the cavitation issue as they fail to realistically incorporate phase change conditions from liquid to vapor and vice versa. The literature review also shows that all but one published paper concerning heterogeneous slip/no-slip bearing analysis used the isothermal model. The exception is the work of Bhattacharya et al. [11], where thermal effects are considered. Considering the effect of both the thermal and the multiphase cavitation is a significant factor in exploring (thermo-) hydrodynamic problems. Therefore, in order to obtain a more accurate prediction, in this work a multiphase thermo-hydrodynamic (THD) model has been generated, considering lubricant phase change, viscous dissipation, and the solution of the energy equation in the fluid domain. This realistic cavitation treatment via multiphase analysis would enable the prediction of the lubricant rupture as well as the reformation boundaries. Further, the contribution of this paper is to numerically study the characteristics of the heterogeneous slip/no-slip journal bearing concerning thermal, and cavitation behaviour, as well as its tribological performance, using a combined solution of Navier-Stokes and vapor transport equations. In this way, the continuity of multiphase flow, mass and momentum continuity analysis can be achieved.

\section{Theory}

\subsection{Governing Equations}

In this work, a CFD (computational fluid dynamics) model has been employed to calculate the lubricant flow, pressure generation, and heat dissipation in the fluid domain. For a continuous fluid medium, the momentum and continuity equations from the principles of classical fluid mechanics are employed to calculate the behaviour of the lubricant.

The mass conservation equation is given as:

$$
\nabla \cdot V=0
$$


The momentum conservation equation reads:

$$
\rho(V . \nabla) V=-\nabla p+\nabla \cdot(\mu \nabla V)
$$

where $V$ is the fluid velocity vector, $\rho$ is the fluid density, $p$ is the fluid hydrodynamic pressure, and $\mu$ is the fluid viscosity.

In the present study, heat transfer is involved, and thus an additional equation for energy conservation is solved. The temperature distribution through the lubricant film can be predicted by solving the following form of the energy equation:

$$
\rho C_{p} V \cdot \nabla T=\nabla \cdot(\lambda \nabla T)-\tau: \nabla V
$$

where $C_{p}$ refers to the liquid specific heat capacity, $T$ refers to the liquid temperature, and $\lambda$ denotes liquid thermal conductivity.

In this work, temperature-dependent viscosity is considered and modelled according to the McCoull and Walther relation [35]. It reads:

$$
\log (\log (v+a))=b-n \log (T)
$$

where $v$ is the kinematic viscosity (in cSt), and $a, b$, and $n$ are constants that depend on the lubricant. The parameters $a, b$, and $n$ for the utilized lubricant (i.e., ISO VG 46 oil) take the values $a=0.7, b=10.0032$, and $n=3.9785$ [35]. For other physical parameters, the following equations represent the fluid thermal conductivity $\lambda$, the fluid specific heat capacity $C_{\mathrm{p}}$, and the fluid density $\rho$, respectively, as a function of temperature [35]:

$$
\begin{gathered}
\lambda=0.1312\left(1-6.3 \times 10^{-4} T\right) \\
C_{p}=1800(1+0.002 T) \\
\rho=\rho_{15.6}[1-0.00063(T-15.6)]
\end{gathered}
$$

\subsection{Slip Modelling}

In reality, the slip boundary on the surface can be engineered by modifying the properties of roughness and wettability $[36,37]$. In the numerical framework, the modified Navier-slip model as shown in Equation (6) is considered. This model states that the slip boundary is shown if the fluid-solid shear stress $\tau$ exceeds a critical value $\tau_{\text {cr }}$. The corresponding slip velocity is governed by $[8,38]$ :

$$
\begin{gathered}
\text { If } \tau<\tau_{\mathrm{cr},}, u_{s}=0 \\
\text { If } \tau \geq \tau_{\mathrm{cr} r}, u_{s}=\left(\tau-\tau_{\mathrm{cr}}\right) \frac{b}{\mu}
\end{gathered}
$$

where $u_{s}$ is the slip velocity, $b$ is the slip length, $\mu$ is the lubricant viscosity (at $40^{\circ} \mathrm{C}$ ), and $\tau_{\mathrm{cr}}$ is the critical shear stress at which the slip boundary is presented. The slip length $b$ shows the level of slip when the surface contacts with a specific lubricant. In a real application, the slip length can be adjusted by employing the appropriate type of hydrophobic monolayer and/or the level of surface (micro) roughness [1-7,39]. Equation (6) expresses that the slip velocity linearly increases with increasing shear stress at a constant slip length $b$. In this study, the user-defined-function (UDF) in the ANSYS FLUENT package is developed to simulate the slip boundary in a deterministic way, based on Equation (7). For all the following computations, the uniform slip length is employed [39]. The high slip length of $100 \mu \mathrm{m}$ is used, whereas the zero critical shear stress is adopted for achieving the optimal load-carrying capacity based on published works $[38,40]$.

\subsection{Cavitation Modelling}

The cavitation phenomenon has been thoroughly studied. The cavitation has a significant effect on the bearing lubrication performance. In real conditions, the cavitation process may occur during the operation of the journal bearing. When the lubricant enters the divergent zone, the film pressure might fall below the saturation vapor pressure, and 
the lubricant would rupture because the liquids cannot support high negative pressure. As mentioned in the earlier section, the cavitation is the primary concern in the lubrication problem, which needs to be modelled appropriately. Therefore, in the present work, the cavitation is modelled using a mixture model representing vapor-liquid two-phase flow. The mixture model solves the mixture equation and prescribes relative velocities to define the dispersed phases [41]. It indicates that the liquid phase changes to the vapor phase when the lubricant film pressure falls below the vaporization pressure. Basically, the mixture model is a simplified full multiphase model but with less expensive computational time [41].

Based on the mixture model, the growth of gas bubbles, which often accompanies the cavitation phenomena, is calculated. For solutions, the cavitation and fluid models are coupled, and the momentum, continuity, and energy equations for the mixture are calculated. In cavitation, the liquid-vapor mass transfer is governed by the vapor transport equation [41]:

$$
\frac{\partial}{\partial t}\left(\alpha_{v} \rho_{v}\right)+\nabla \cdot\left(\alpha_{v} \rho_{v} V_{v}\right)=R_{g}-R_{c}
$$

where $\alpha_{v}$ refers to vapor volume fraction, and $\rho_{v}$ denotes vapor density. $R_{g}$ and $R_{c}$ account for the mass transfer between the liquid and vapor phases in cavitation. They are modelled based on the Rayleigh-Plesset equation, which gives a good approximation of vapor cavitation. This equation represents the growth of a single vapor bubble in a liquid, governed by the following equation:

$$
R_{b l} \frac{d^{2} R_{b l}}{d t^{2}}+\frac{3}{2}\left(\frac{d R_{b l}}{d t}\right)^{2}=\frac{p_{b l}-p}{\rho}-\frac{2 \sigma}{\rho R_{b l}}-4 \frac{\mu}{\rho R_{b l}} \frac{d R_{b l}}{d t}
$$

Neglecting the surface tension and the acceleration of the bubble growth, Equation (8) is simplified to

$$
\frac{d R_{b l}}{d t}=\left(\frac{2}{3} \frac{p_{b l}-p}{\rho}\right)^{\frac{1}{2}}
$$

Equation (9) represents a physical approach to predict the influences of bubble dynamics in the cavitation model. It can also be considered to be an equation for void propagation and, hence, mixture density [42]. In this work, the multiphase cavitation model of Zwart-Gerber-Belamri is adopted due to less computational effort (less running time, relatively higher precision, good convergence, and more robust [41-43]). For the Zwart-Gerber-Belamri model, assuming that all the bubbles have the same size in a system, the final form of the cavitation is as follows:

$$
\begin{gathered}
p \leq p_{v}, R_{g}=F_{\text {evap }} \frac{3 \alpha_{n u c}\left(1-\alpha_{v}\right) \rho_{v}}{R_{b l}} \sqrt{\frac{2}{3} \frac{p_{v}-p}{\rho}} \\
p \geq p_{v}, R_{c}=F_{\text {cond }} \frac{3 \alpha_{v} \rho_{v}}{R_{b l}} \sqrt{\frac{2}{3} \frac{p-p_{v}}{\rho}}
\end{gathered}
$$

where $p_{v}$ is the liquid saturation vapor pressure at the given temperature, $F_{\text {evap }}$ (evaporation coefficient) and $F_{\text {cond }}$ (condensation coefficient) are empirical constants with recommended values of $F_{\text {evap }}=50$ and $F_{\text {cond }}=0.01, R_{b l}$ bubble radius $=10^{-6} \mathrm{~m}$, and $\alpha_{n u c}$ is the nucleation site volume fraction $=5 \times 10^{-4}$, based on the work of Zwart et al. [42].

\section{Computational Analysis}

\subsection{Geometric Model}

In the present work, a three-dimensional CFD-based thermo-hydro-dynamic model of a journal bearing system has been generated. In order to clarify the meaning of the main parameters involved and the geometry of the computational domain, the schematic of the heterogeneous slip/no-sip journal bearing at the rotational velocity $n$ is depicted in 
Figure 1. The slip/no-slip configuration, as shown in Figure 2, is applied on the stationary surface representing the bearing sleeve. In the present work, the slip/no-slip configuration bearing with a rectangular shape is of particular interest, based on the work of Fortier and Salant [8], Zhang et al. [12], and Cui et al. [17]. The slip is partially employed on the convergent area for extra generation of the load support $[12,20]$. In terms of the slip zone, for all following computations, the slip area is arranged from the angular coordinates, namely the circumferential angle $\theta$ of $0^{\circ}$, with the reference position measured at the $h_{\text {max }}$, to the $\theta$ of $180^{\circ}$, as indicated in Figure 1. It was proven that such a pattern (i.e., rectangular shape, and partial slip surface zone) gives a better tribological performance with higher hydrodynamic pressure in a narrower cavitation region. In the frame of both experimental and theoretical studies, it is believed that the flow characteristic during lubrication in the journal bearing can be altered by introducing the heterogeneous slip/no-slip pattern in a more positive way, concerning the improvement of the tribological performance. Table 1 describes the parameters of the simulation model, including the geometry, operational condition, and the corresponding lubricant properties.

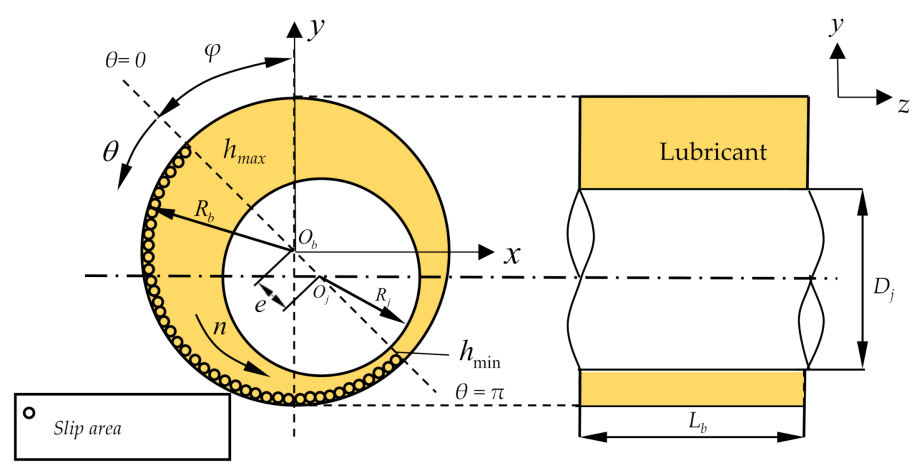

Figure 1. Schematic diagram of a heterogeneous slip/no-slip journal bearing.

Table 1. Parameters of the model.

\begin{tabular}{ccc}
\hline Parameters & Value & Unit \\
\hline Journal radius $R_{j}$ & 40 & $\mathrm{~mm}$ \\
Radial clearance $c$ & 0.04 & $\mathrm{~mm}$ \\
Bearing length $L_{b}$ & 80 & $\mathrm{~mm}$ \\
Attitude angle $\varphi$ & 30 & $\mathrm{deg}$ \\
Rotational velocity $n$ & $100 ; 500 ; 1000 ; 3000 ; 5000$ & $\mathrm{rpm}$ \\
Oil dynamic viscosity $\mu\left(40^{\circ} \mathrm{C}\right)$ & 0.0125 & $\mathrm{~Pa} . \mathrm{s}$ \\
Oil density $\rho\left(40^{\circ} \mathrm{C}\right)$ & 850 & $\mathrm{~kg} / \mathrm{m}^{3}$ \\
Oil specific heat $C_{p}\left(40^{\circ} \mathrm{C}\right)$ & 1944 & $\mathrm{~J} / \mathrm{kg} . \mathrm{K}$ \\
Oil thermal conductivity $\lambda\left(40^{\circ} \mathrm{C}\right)$ & 0.12789 & $\mathrm{~W} / \mathrm{m} . \mathrm{K}$ \\
Vapor dynamic viscosity $\mu_{v}$ & $2 \times 10^{-5}$ & $\mathrm{~Pa} . \mathrm{s}$ \\
Vapor density $\rho_{v}$ & 10.95 & $\mathrm{~kg} / \mathrm{m}^{3}$ \\
Vapor specific heat $C_{p \mathrm{v}}$ & 2430 & $\mathrm{~J} / \mathrm{kg} \cdot \mathrm{K}$ \\
Vapor thermal conductivity $\lambda_{\mathrm{v}}$ & 0.0178 & $\mathrm{~W} / \mathrm{m} . \mathrm{K}$ \\
Vapor saturation pressure $p_{v}$ & 29,185 & $\mathrm{~Pa}$ \\
\hline
\end{tabular}




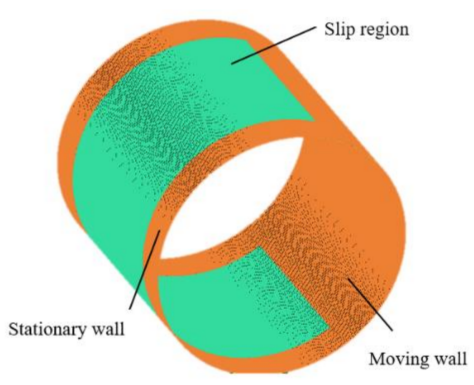

(a)

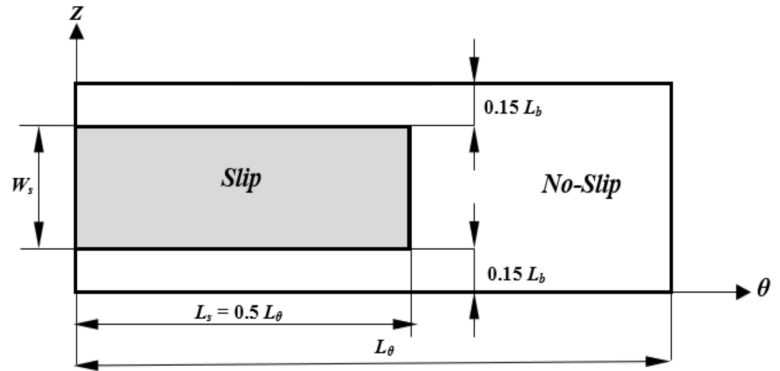

(b)

Figure 2. Slip/no-slip configuration for journal bearing studied, (a) in isometric view, (b) in top view.

\subsection{Solution Set Up}

In this work, the spatial fluid domain is discretized with a three-dimensional mesh, consisting of hexahedral finite control volumes, as reflected in Figure 3. The number of element layers in the radial and circumferential directions are chosen as the most affecting mesh parameters. To capture the flow change due to the sudden change in slip and noslip boundary, four grid layers of the fluid domain (in the radial direction) have been built. In addition, to determine the accuracy of the simulation results provided, with optimum grid densities, a grid dependence study is performed for the given problem. In this way, computational simulations to ensure independent mesh results are performed using different mesh sizes. Based on the grid-independent solution, the grid number used for the calculations in the present study is around 250,000 with an element size of $0.5 \mathrm{~mm}$.

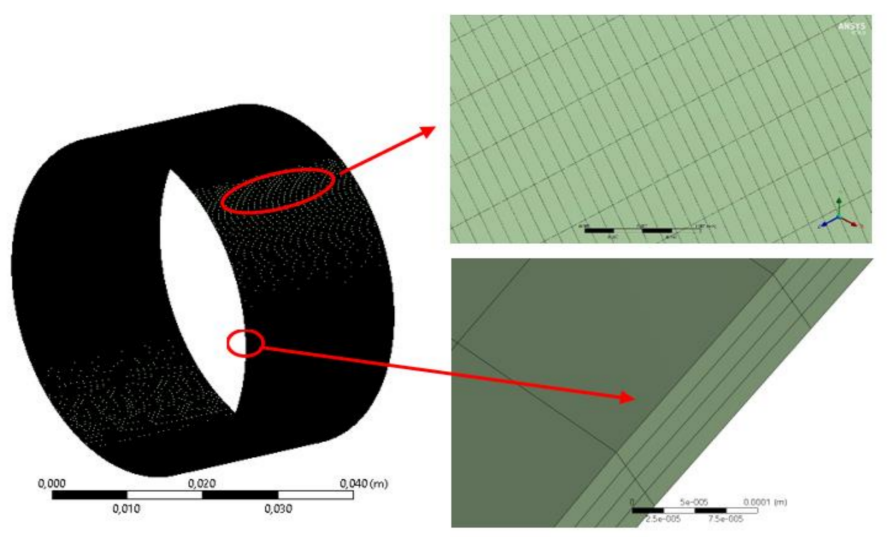

Figure 3. Schematic of grid generation for computational fluid dynamics- (CFD-) based thermohydro-dynamic analysis.

In this work, the cavitation regions and the hydrodynamic pressure are computed with the MIXTURE model during the calculation in ANSYS FLUENT ${ }^{\circledR}$ software. As depicted in Figure 4, the boundary condition of the computational domain for CFD-based thermohydro-dynamic analysis is set as follows: the pressure at the inlet and outlet boundaries are taken as the ambient pressure, i.e., zero pressure. At the inlet section, oil enters into the bearing with a uniform temperature of $300 \mathrm{~K}$. At the outlet section, the temperature is set to $318 \mathrm{~K}$. 


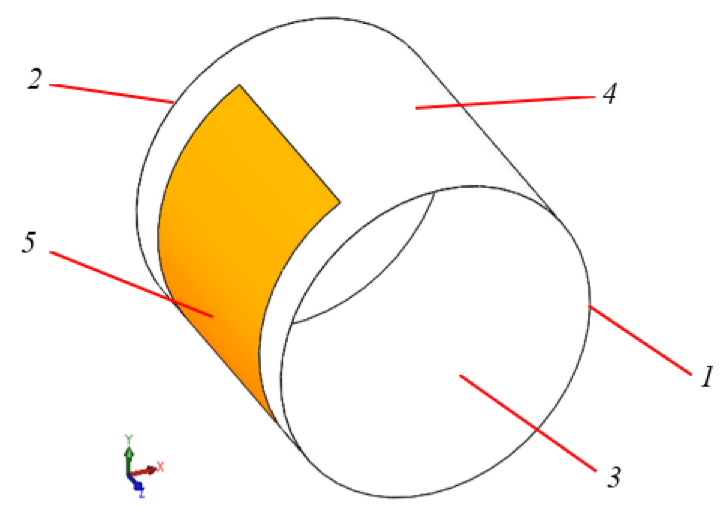

Figure 4. Boundary condition of the computational: (1) pressure and temperature inlet (2) pressure and temperature outlet (3) moving wall (4) no-slip stationary wall (5) slip stationary wall.

In this simulation, the pressure-based solver and the SIMPLE pressure-velocity coupling method are employed to obtain the results quickly. For the momentum equations, the second-order upwind discretization scheme is used, whereas the QUICK discretization scheme is employed for the volume fraction. Furthermore, the first-order upwind scheme is used for discretization of turbulent kinetic energy and the turbulent dissipation rate. The convergence precision employed in the present study is $1.0 \times 10^{-4}$ and $1.0 \times 10^{-6}$ for the pressure and energy, respectively.

\section{Results and Discussion}

As discussed by Meng and Khonsari (2018), 3D CFD simulation can reflect more detailed flow behaviour, including the temperature distribution and the fluid cavitation, in comparison with the Reynolds equation, even with mass-conserving conditions. In this section, the simulation results of 3D CFD-based thermo-hydro-dynamic analysis for the journal bearing with heterogeneous slip/no-slip patterns are presented.

\subsection{Validation}

In order to prove that the CFD method and its solution setup can be employed for thermo-hydro-dynamic (THD) analysis of the journal bearing, it must be shown that the results are correct and with specified accuracy. Here, the results in terms of the hydrodynamic pressure and the wall temperature distribution in the present study are compared with the numerical data of Li et al. [44] as a reference under the same input conditions and computed operational parameters, with the exception that in the present study deformation is not taken into account in the CFD model. The comparison for these results is depicted in Figure 5. The developed numerical method gives a maximum hydrodynamic value of $4.77 \mathrm{MPa}$ ( $3.8 \%$ larger) at the rotational speed of $3000 \mathrm{rpm}$, and an eccentricity ratio of 0.8 as compared to $4.96 \mathrm{MPa}$ given by Li et al. [44]. Based on Figure $5 \mathrm{~b}, \mathrm{c}$, the deviation between the present study and the work of Li et al. [44] is about $0.34 \%$ and $0.20 \%$, respectively, in terms of maximum moving wall temperature and maximum stationary wall temperature. In conclusion, the results of the present study are in good agreement with those of the work of Li et al. [44], suggesting validation of the developed numerical solution code. In what follows, all the simulations are performed based on the present code. 


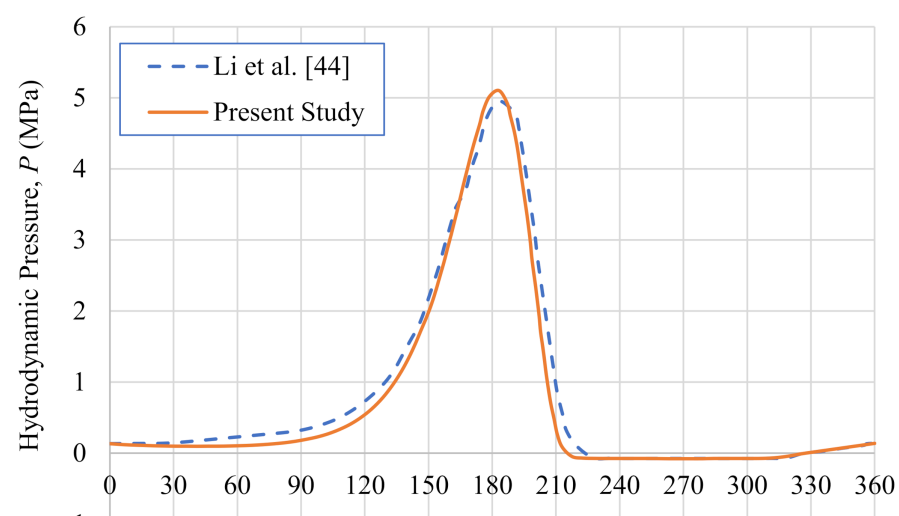

Circumferential Angle, $\theta\left(^{\circ}\right)$

(a)

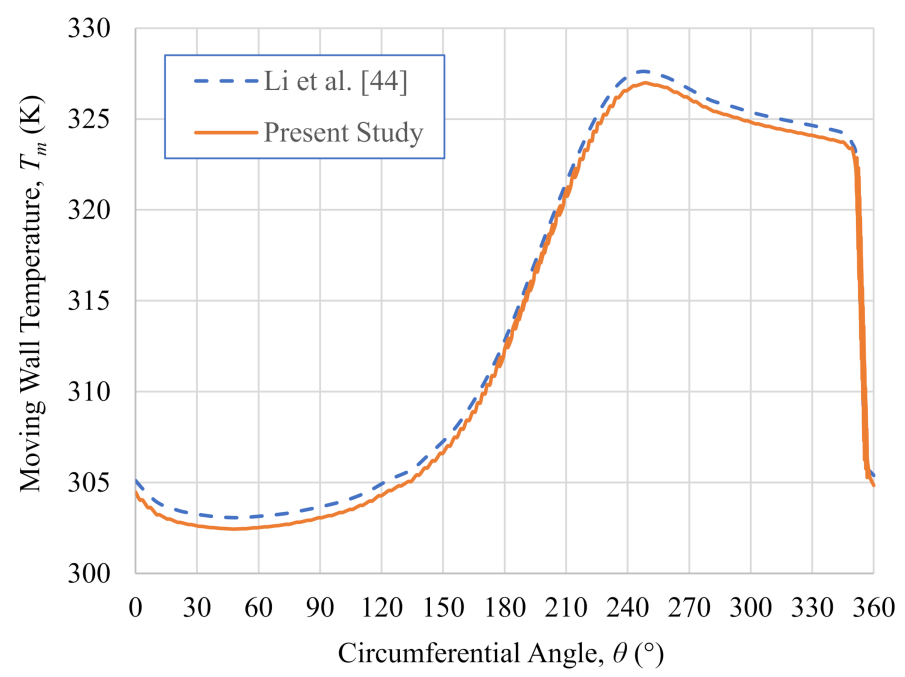

(b)

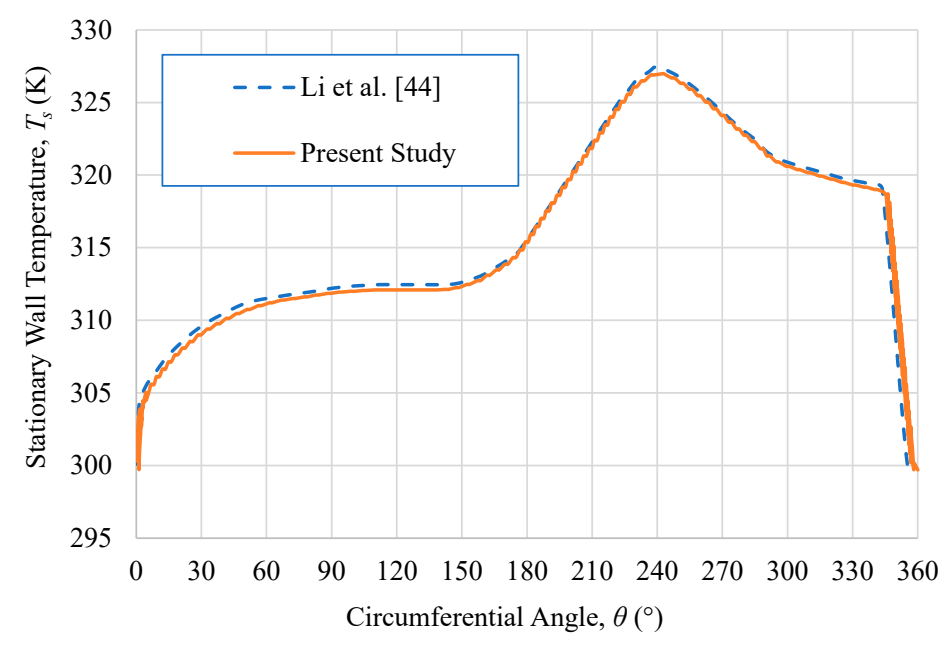

(c)

Figure 5. Comparison between the result of the present study and the literature [44] in terms of (a) hydrodynamic pressure, (b) moving wall temperature, (c) stationary wall temperature. The numerical results are evaluated at mid-plane $\mathrm{z} / L$ of 0.5 , rotational speed $n$ of $3000 \mathrm{rpm}$, and eccentricity ratio $\varepsilon$ of 0.8 . 


\subsection{Effect of Slip Zone}

In this section, the simulation results are presented for the journal bearing when the shaft is eccentric to the bearing position by comparing two kinds of bearing, i.e., conventional (no-slip) bearing and heterogeneous slip/no-slip bearing. Parameters studied are the hydrodynamic pressure, the volume of fraction, the temperature and the loadcarrying capacity. The load-carrying capacity that the bearing will support is obtained by integrating the hydrodynamic pressure around the journal. The bearing with the eccentricity ratio of 0.6 is of particular interest. Computations have been made with the primary aim of answering the question: "How does the heterogeneous slip/no-slip pattern affect tribological performance and thermal characteristics". To determine the flow regime in the studied journal bearing, both the critical Reynolds number $\left(\operatorname{Re}_{c}=\right.$ $\rho_{f} \times \pi n D_{j} \times c \times(1-\varepsilon) / 60$ and the real Reynolds number $\left(R e_{r}=\rho_{f} \times \pi n D_{j} \times c /(60 \times \mu)\right)$ are solved. For the eccentricity ratio of 0.6 studied here, the real Reynolds number $R e_{r}$ calculated for each rotational speed $n$, as indicated in Table 1 , is always larger than the critical one $R e_{c}$. For example, for $n=5000 \mathrm{rpm}$, the $R e_{r}$ equals 56.97, which is two times the value of $R e_{c}$. From the physical point of view, this indicates that turbulence will be exhibited in the lubricant. Consequently, from the numerical point of view, the turbulence model must be taken into account for the lubrication analysis. In the present calculation, the standard turbulent kinetic energy $k$ and turbulent dissipation rate $e$ models [41] are employed to solve the Reynolds stress. To note, for the momentum equation, the Reynoldsaveraged Navier-Stokes (RANS) equation is used.

Figure 6 depicts the hydrodynamic pressure for two kinds of bearing, i.e., conventional (no-slip) bearing and heterogeneous slip/no-slip bearing for the eccentricity ratio $\varepsilon$ of 0.6 and the rotational speed $n$ of $3000 \mathrm{rpm}$. It can be observed that, compared to the classical (no-slip) pattern, the heterogeneous slip/no-slip bearing is very effective in producing more hydrodynamic pressure. The maximum hydrodynamic pressure of the heterogeneous slip/no-slip bearing can be increased by up to $90 \%$ when compared to what traditional hydrodynamics (no-slip) predicts for a lubricated bearing with the same slope incline ratio. Based on Figure 6, it can also be observed that the angle of the pressure rise has shifted when the slip is introduced. In the case of the conventional bearing, the pressure starts to increase at the circumferential angle $\theta$ of $90^{\circ}$ and drops to saturated pressure at $\theta=195^{\circ}$. For the heterogeneous slip/no-slip bearing, it is clear that the pressure gradient is higher than that of the conventional bearing. The pressure starts to rise at the angle $\theta=120^{\circ}$ and falls to the saturated pressure at the $\theta=220^{\circ}$. As can be seen in Figure 7, depicting the comparison of the contour of hydrodynamic pressure between the conventional (no-slip) bearing and the heterogeneous slip/no-slip bearing, there is a narrowing high-pressure zone when the slip boundary is employed. The best possible explanation is that the slip boundary at $\theta=180^{\circ}$ produces a sudden change of boundary, similar to the sudden change of geometry, as found in the Rayleigh step bearing. This boundary generates the high-pressure gradient while lowering the high-pressure zone. The double effect of these phenomena yields a much higher load-carrying capacity. As observed in Figure 8, the increase in the loadcarrying capacity due to the presence of the heterogeneous slip/no-slip pattern ranges from $20-100 \%$ depending on the rotational shaft speed. For example, for low rotational speed $n$ of $500 \mathrm{rpm}$, the load-carrying capacity can be improved up to $100 \%$ higher in comparison with the conventional bearing. For high rotational speed $(n=5000 \mathrm{rpm}$ in this case), the discrepancy in the load-carrying capacity predicted by the heterogeneous slip/no-slip pattern is around $20 \%$ higher than that produced by the conventional bearing. In other words, there is a threshold value of the rotational speed in which the advantage of the load-carrying capacity by the engineered slip surface can reduce. However, in general, Figure 8 reveals that the heterogeneous slip/no-slip bearing is superior to the conventional bearing, irrespective of the rotational speed. 


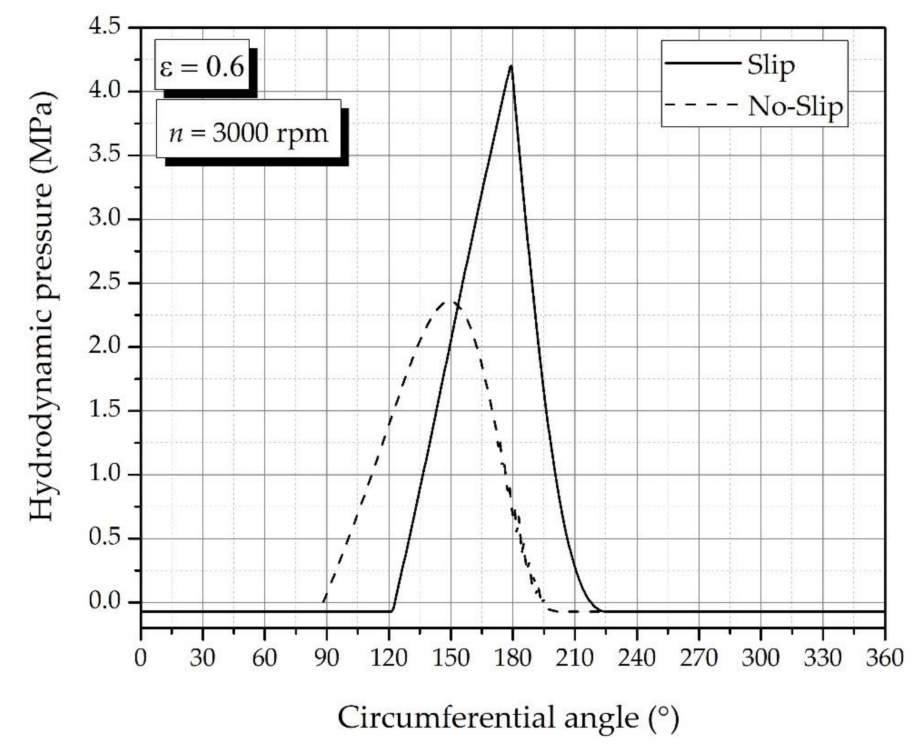

Figure 6. Comparison of the profile of hydrodynamic pressure between the conventional (no-slip) bearing and the heterogeneous slip/no-slip bearing. All results are evaluated at $z / L=0.5$ and $n=3000 \mathrm{rpm}$.

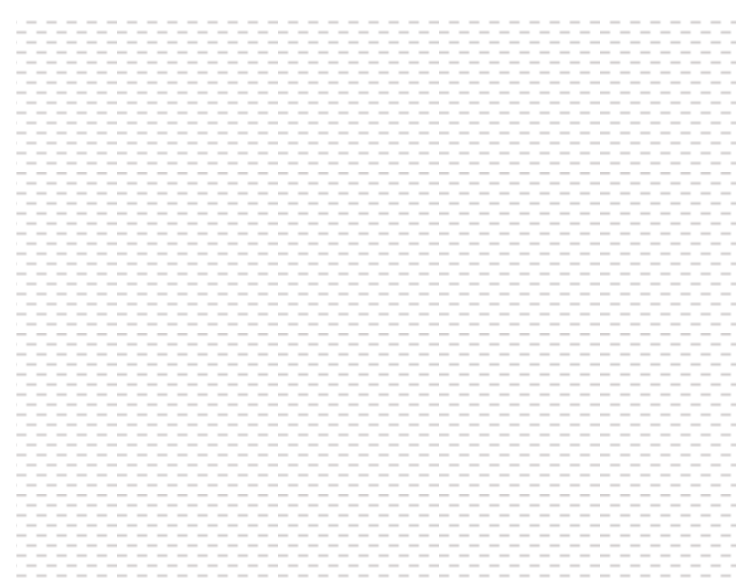

(a)
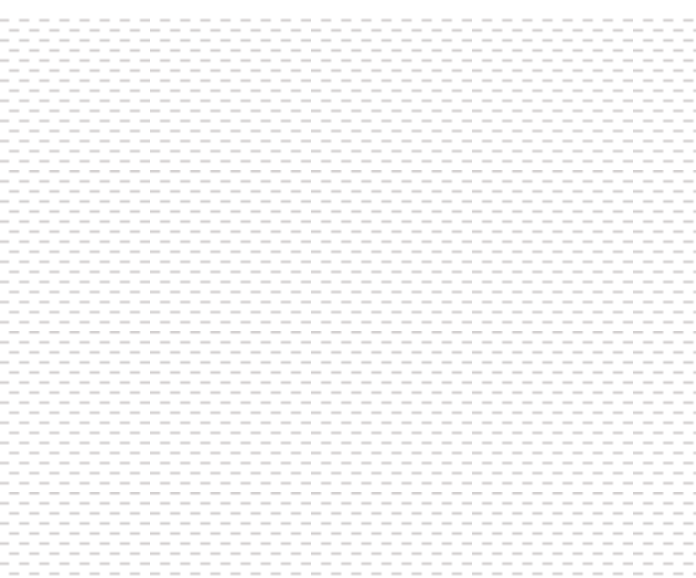

(b)

Figure 7. Comparison of the contour of hydrodynamic pressure between (a) the conventional (no-slip) bearing and (b) heterogeneous slip/no-slip bearing. All results are evaluated at $n=3000 \mathrm{rpm}$.

Another interesting finding regarding the benefit of the use of a heterogeneous slip/noslip pattern is in terms of temperature distribution over the contacting surface. Figure 9 depicts the comparison of the temperature profile between the conventional (no-slip) bearing and the heterogeneous slip/no-slip bearing. The temperature distribution in the plot suggests that the slip boundary in heterogeneous slip/no-slip form is able to decrease the temperature profile significantly. Meanwhile, it can also be observed that the location of the temperature jump shifts from the bearing angle $\theta=90^{\circ}$ to the $\theta=120^{\circ}$. Color distribution in the contour of temperature, as shown in Figure 10, illustrates that the high-temperature zone occurs at the mid-plane both in the case of conventional and heterogeneous slip/no-slip patterns. Looking at the configuration of the oil-lubricant temperature, it can be revealed that the differences in the oil-lubricant temperature profile for the two kinds of bearings considered here exist in the values of local temperature along the circumferential contact area. Decrease in the maximum temperature of up to $25 \%$ can be achieved by using the heterogeneous slip/no-slip pattern. 


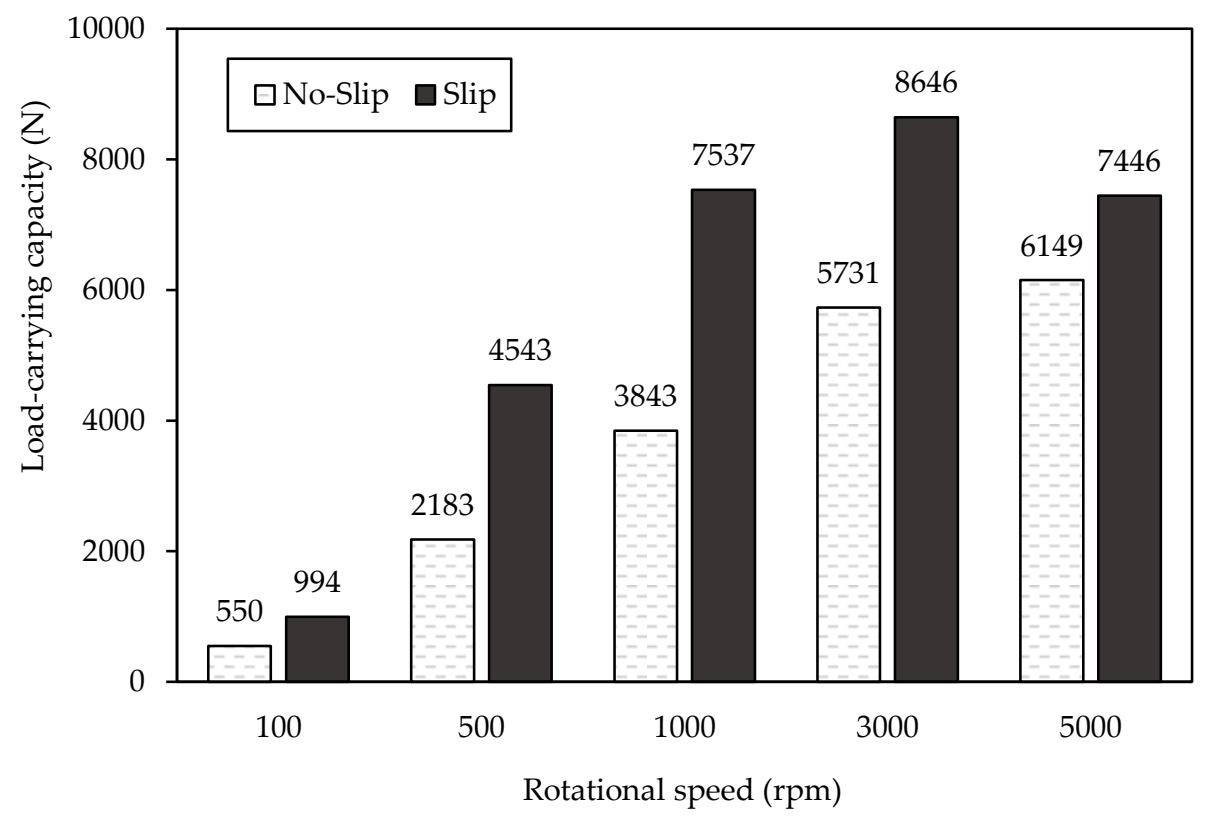

Figure 8. Comparison of the load-carrying capacity between the conventional (no-slip) bearing and the heterogeneous slip/no-slip bearing at different rotational speeds. All results are evaluated at $z / L=0.5$.

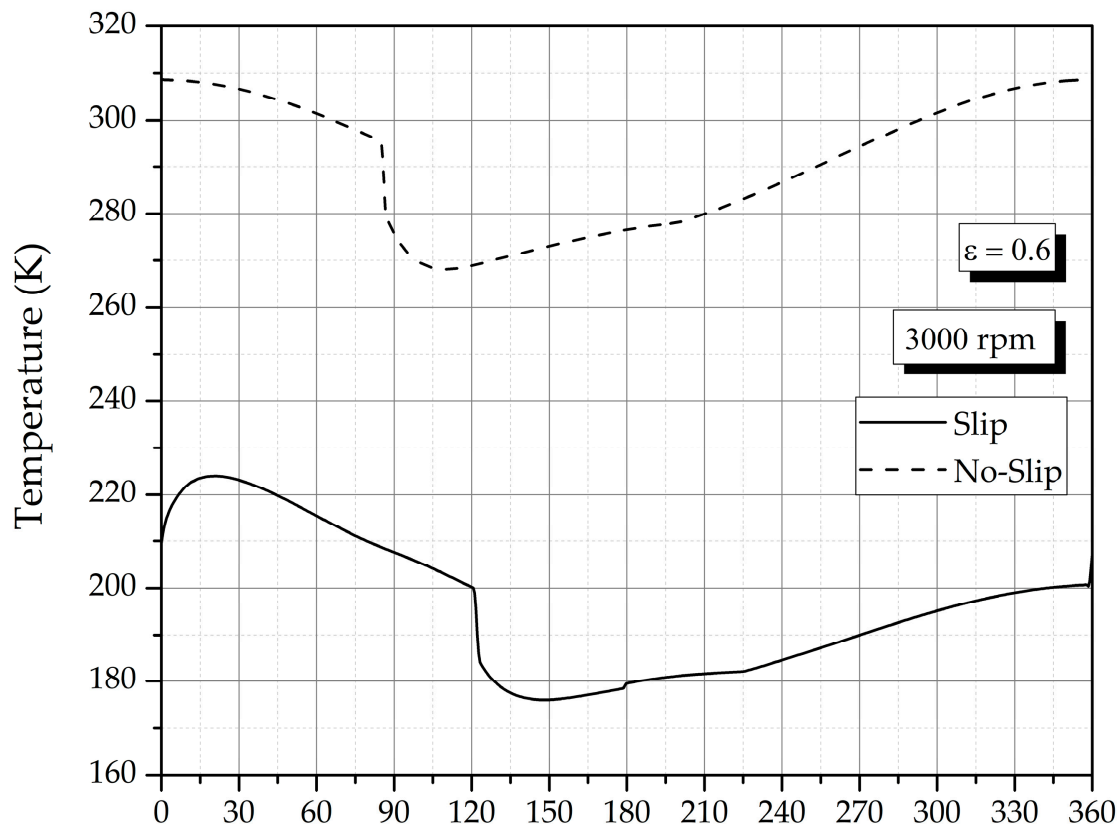

Circumferential angle $\left(^{\circ}\right)$

Figure 9. Comparison of the profile of temperature between the conventional (no-slip) bearing and heterogeneous slip/no-slip bearing. All results are evaluated at $z / L=0.5$ and $n=3000 \mathrm{rpm}$.

Figure 11 shows the comparison of the profile of vapor volume fraction between the conventional (no-slip) bearing and the heterogeneous slip/no-slip bearing for the case of high journal rotational speed (i.e., $n=3000 \mathrm{rpm}$ ). Several specific features can be found based on Figure 11. Firstly, the cavitation occurs at two zones for all types of bearing studied: the specific zone in the converging area and the particular zone in the diverging area. In the conventional (no-slip) bearing, for the first cavitated zone the cavitation is located at a bearing angle of $0-90^{\circ}$. For the second cavitated area in the diverging zone, it seems that the cavitation starts from $195-360^{\circ}$. For the case of the heterogeneous slip/no- 
slip bearing, the first cavitated zone is larger than that that of the conventional bearing. It seems that the cavitated zone in the converging zone exists at the bearing angle $0-122^{\circ}$, while for the cavitated area in the diverging zone of the heterogeneous slip/no-slip bearing, as can be seen in Figure 11, the cavitation starts from $225-360^{\circ}$. In other words, there is a shift in the non-cavitated zone of the bearing when the artificial slip boundary is employed. The reason for this phenomenon is that the slip boundary retards the cavitation occurrence. This finding strengthens the analytical result of Muchammad et al. [45], who pointed out the positive effect of the slip in reducing cavitation. Secondly, the heterogeneous slip/noslip journal bearing has a higher value of cavitation volume fraction for the cavitated zone in the converging zone in comparison to the conventional bearing, and it has a lower value of cavitation volume fraction for the cavitated zone in the diverging zone. The appearance of this characteristic, as can also be observed in Figure 12 reflecting the comparison of the contour of vapor volume fraction between the conventional (no-slip) bearing and the heterogeneous slip/no-slip bearing, is because the slip at the inlet has triggered more oil vapor bubbles to be expelled. When the lubricant is diverging, the oil lubricant is squeezed and pushes the oil vapor oil out of the journal.

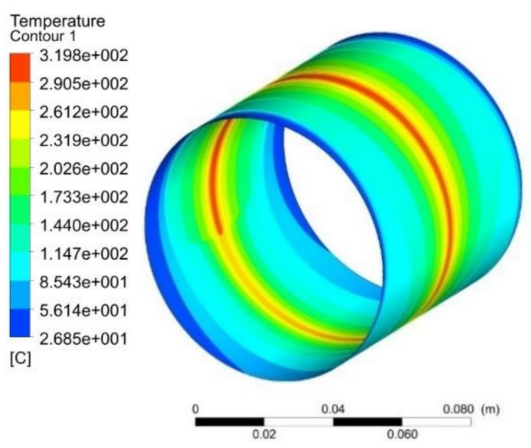

(a)
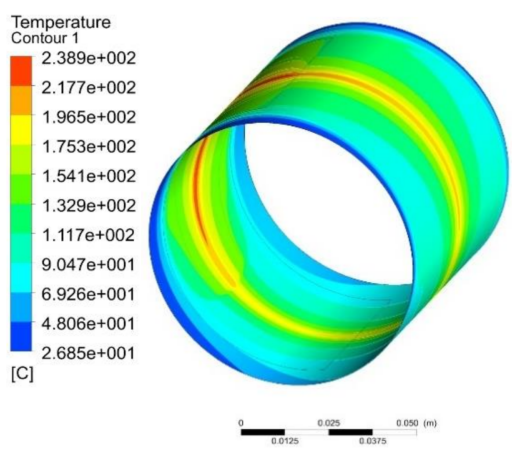

(b)

Figure 10. Comparison of the contour of temperature between (a) the conventional (no-slip) bearing and (b) the heterogeneous slip/no-slip bearing. All results are evaluated at $n=3000 \mathrm{rpm}$.

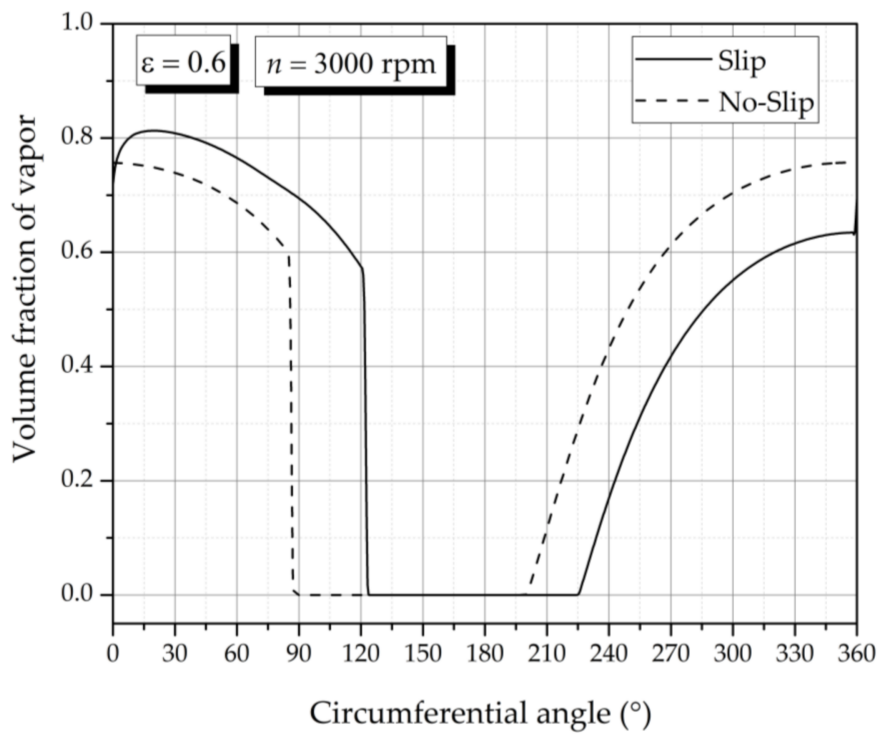

Figure 11. Comparison of the profile of vapor volume fraction between the conventional (no-slip) bearing and the heterogeneous slip/no-slip bearing. All results are evaluated at $z / L=0.5$ and $n=3000 \mathrm{rpm}$. 


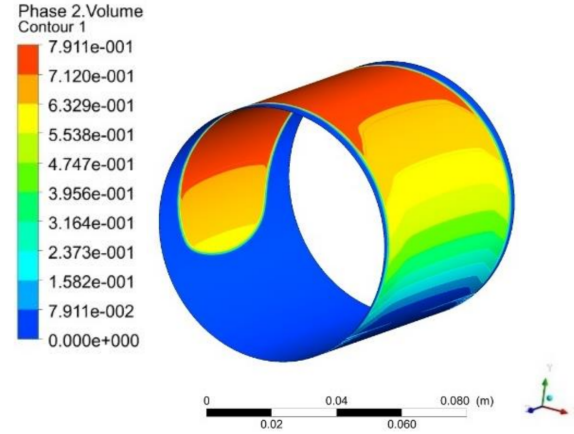

(a)

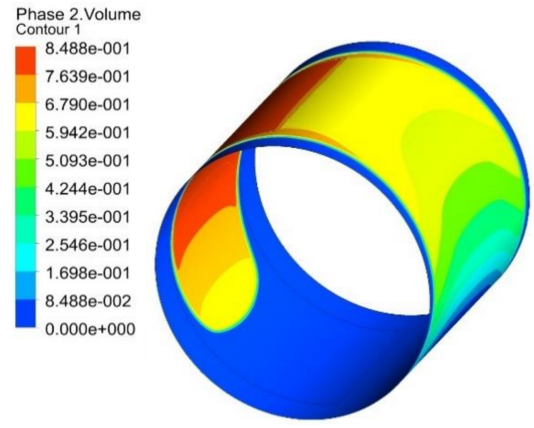

(b)

Figure 12. Comparison of the contour of vapor volume fraction between (a) the conventional (no-slip) bearing and (b) the heterogeneous slip/no-slip bearing. All results are evaluated at $n=3000 \mathrm{rpm}$.

As a concluding remark, based on this section's results, it is beneficial to engineer the stationary surface by introducing the heterogeneous slip/no-slip pattern for the journal bearing. The numerical results indicate that increased load carrying capacity and reduced temperature can be achieved when the heterogeneous slip/no-slip pattern is applied.

\subsection{Effect of Rotational Speed}

The effect of the rotational speed on the thermo-hydro-dynamic response of the journal bearing with different surface conditions is explored in this section. The rotational speed values are chosen to be 100, 500,1000, 3000 and $5000 \mathrm{rpm}$. The hydrodynamic pressure, the temperature, vapor volume fraction, and load-carrying capacity are of particular interest.

Figure 13 depicts the effect of the rotational speeds on the hydrodynamic pressure behaviour of the journal bearing. It is found that the maximum pressure of lubricant film increases with the increase in the rotational speed. The results also reveal that increasing the rotational speed increases the pressure gradient. For example, the maximum pressure of the bearing with rotational speed $n$ of $5000 \mathrm{rpm}$ seems to be the highest at around $5534 \mathrm{kPa}$, about nine times higher than that having the lowest rotational speed ( $n=100 \mathrm{rpm}$ in this case). The location of the maximum film pressure is observed to exist at the bearing angle of $180^{\circ}$ for all values of the rotational speed considered here. From Figure 13, it is also highlighted that the high-pressure zone widens when decreasing the rotational speed. This phenomenon can be observed in more detail in Figure 14, illustrating the contour of the hydrodynamic pressure of heterogeneous slip for all values of rotational speed. Figure 14 implies that, the higher the rotational speed, the narrower the high-pressure zone, but with higher values. This is as expected because when the shaft speed is increased, the velocity of lubricant also increases. This means that the kinetic energy of the lubricant is increased, and as a consequence the increased part of this kinetic energy will be transformed into pressure energy, thereby increasing the local hydrodynamic pressures.

Based on Figure 13, it is also found that the pressure characteristics in the divergent region of the heterogeneous slip/no-slip bearing are similar, irrespective of the rotational speed. The result shows that, at a bearing angle of around $220^{\circ}$, the hydrodynamic pressure drops to saturated pressure for all values of the rotational speed. This indicates that the cavitation occurs in particular in the diverging region. 


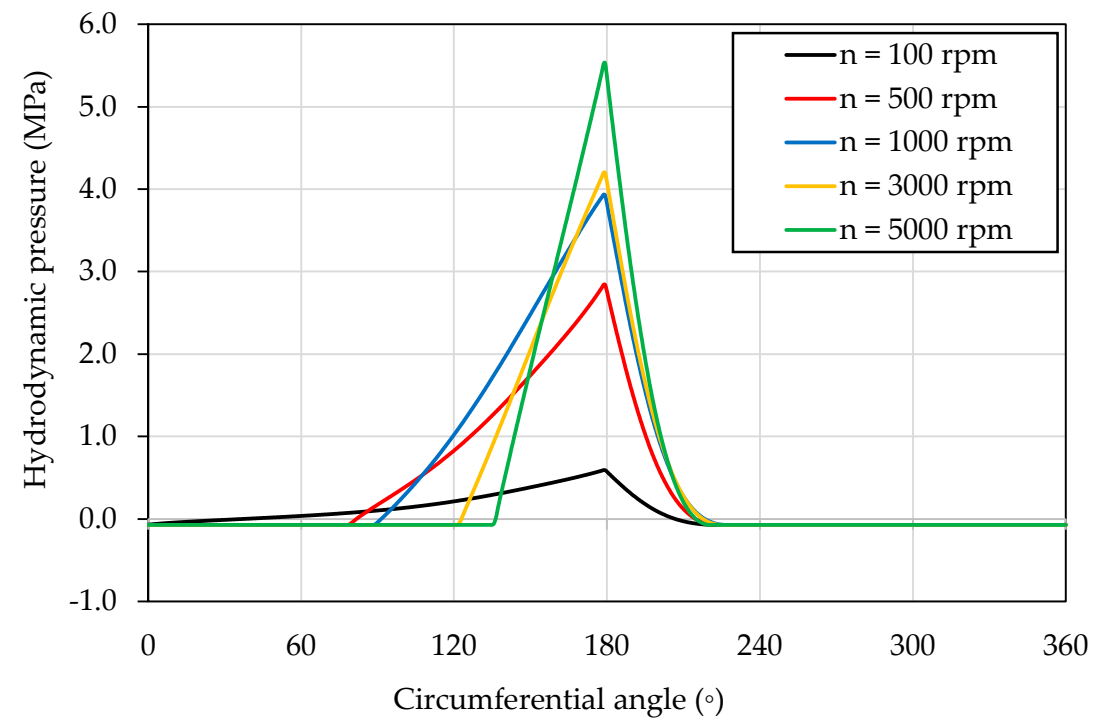

Figure 13. Hydrodynamic pressure profile of the heterogeneous slip/no-slip bearing for different rotational velocity $n$. All results are evaluated at $z / L=0.5$.
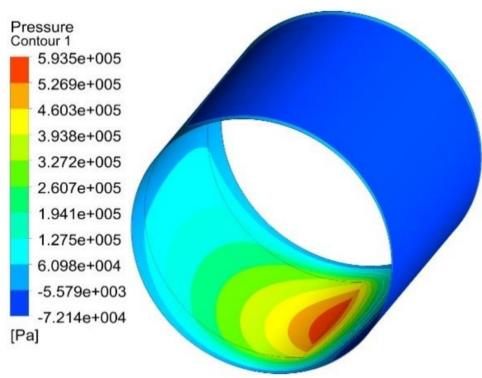

$\overbrace{(a)}^{0.0125}$
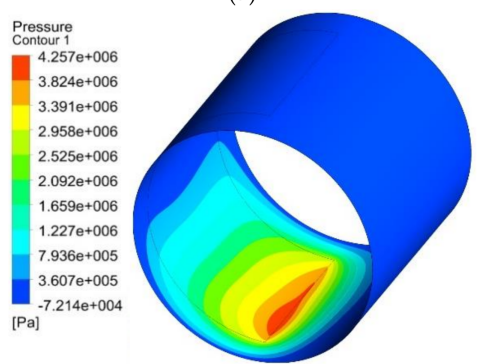

(c)
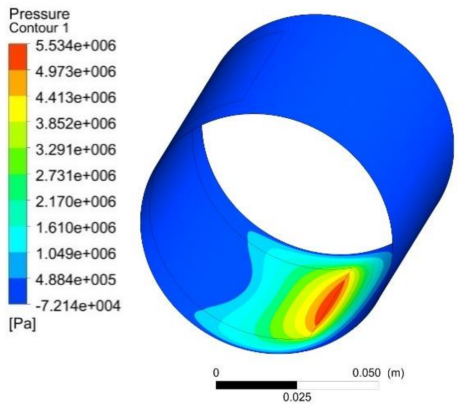

(e)

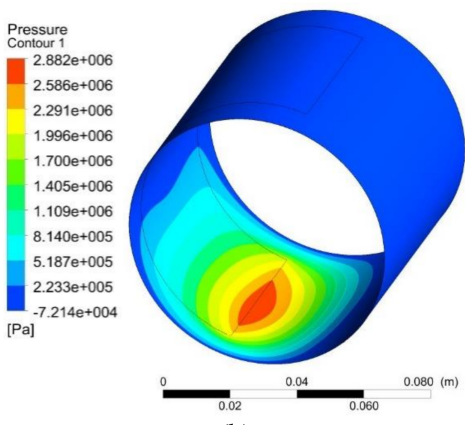

(b)

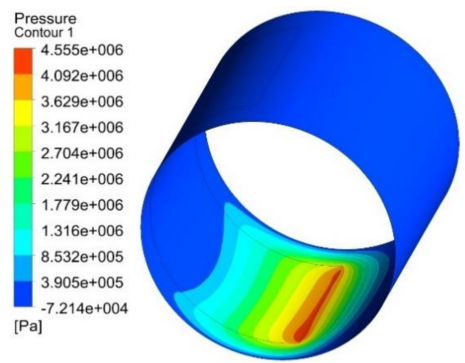

-

(d) 
Figure 15 shows the volume fraction of the oil vapor in the heterogeneous slip/noslip bearing for various rotational speeds. Several features can be drawn from Figure 15. Firstly, the distribution of the volume fraction of vapor goes on increasing with increase in the shaft rotation speed. For the geometry of the heterogeneous slip/no-slip bearing and the operation condition considered here, the distribution of the volume fraction of vapor becomes significant when the shaft rotation speed $n$ is equal to $500 \mathrm{rpm}$ or higher. It seems that the cavitation starts to occur in the bearing angle of $0^{\circ}$, in which the location of the maximum film thickness is determined and finishes somewhere in the converging area, depending on the values of the rotational speed. The question may arise from this phenomenon, why does cavitation present at the converging area for higher rotational speed? To answer this, the contours of vapor volume fraction varying with rotational speeds are illustrated in Figure 16. From Figure 16, it can be found that the heterogeneous slip/no-slip located at the bearing angle of $0^{\circ}$ may become a trigger for inducing the cavitation. This phenomenon can be considered as a geometry jump, which is similar to the Rayleigh step bearing. With higher rotating speed, the resulting negative pressure effect at the boundary of the slip becomes stronger and reaches saturated pressure, which leads to the occurrence of cavitation. With the increase in the rotational speed, the journal drags more oil vapor into the converging region's start location (i.e., the maximum film thickness location). In other words, when the film is converging, the lubricant is squeezed and pulls the vapor bubble in the bearing. Therefore, it seems that the higher $n$, the larger the distribution of the vapor volume fraction.

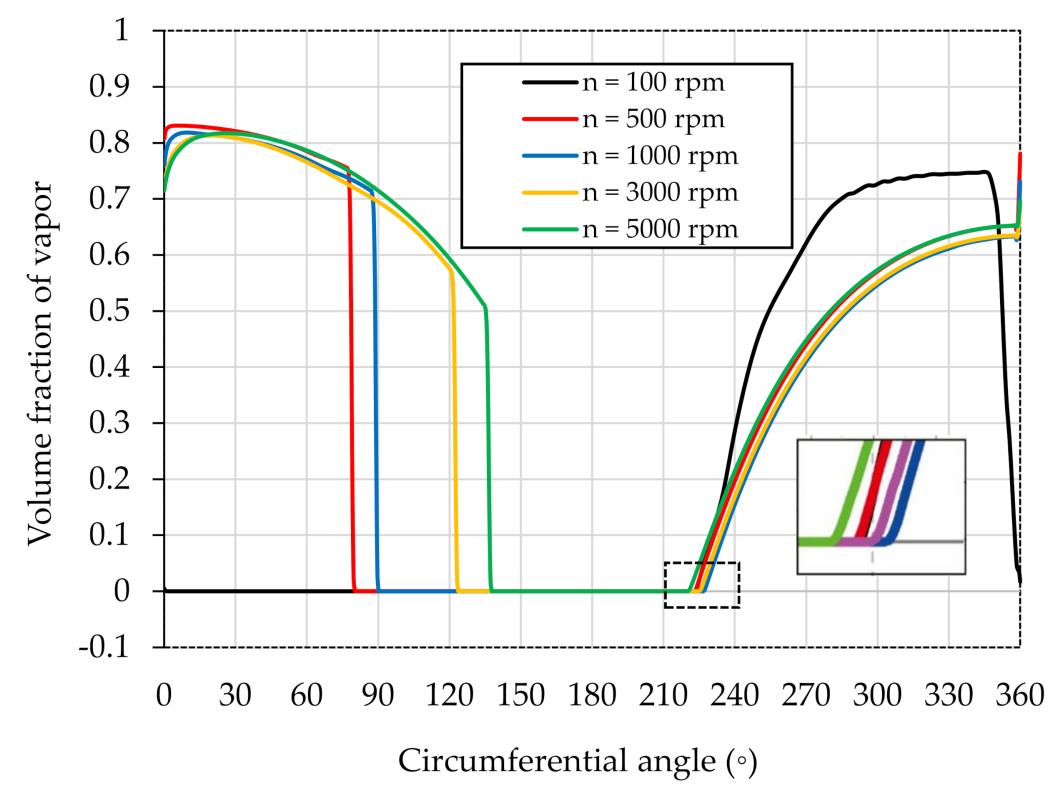

Figure 15. Profile of vapor volume fraction of the heterogeneous slip/no-slip bearing for different rotational velocity $n$. All results are evaluated at $z / L=0.5$.

Secondly, based on Figure 15, it can be observed that, for all values of the rotational speed $n$, cavitation occurs at the bearing angle of around $225^{\circ}$. Unlike the effect of the rotational speed on the vapor volume fraction in the convergent area, the effect of the rotational speed in the diverging area is insignificant. It is found that there is no significant difference in the starting location of the cavitation in the divergent zone. However, for the case of $n=100 \mathrm{rpm}$, the volume fraction of oil vapor has the highest distribution compared to others. Later, less vapor is observed when the lubricant enters the convergent zone, indicating that the vapor changes to the liquid phase. For the case of bearings with higher rotational speed (i.e., $n>100 \mathrm{rpm}$ in this study), the volume fraction of vapor in the divergent zone has a similar path. Generally speaking, for higher $n$ the heterogeneous slip/no-slip pattern in the convergent zone has triggered the cavitation phenomena along the contacting surface, becoming more evident at the convergent zone. 


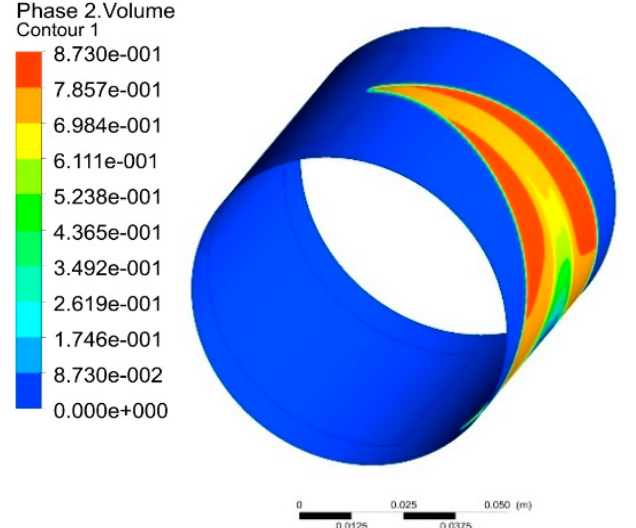

(a)

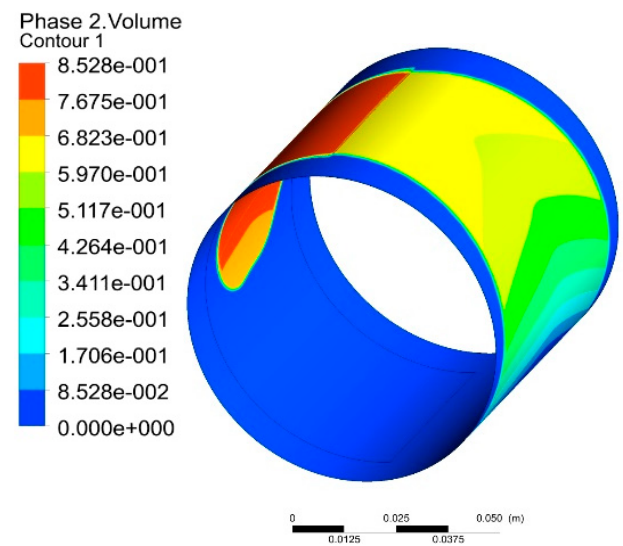

(c)

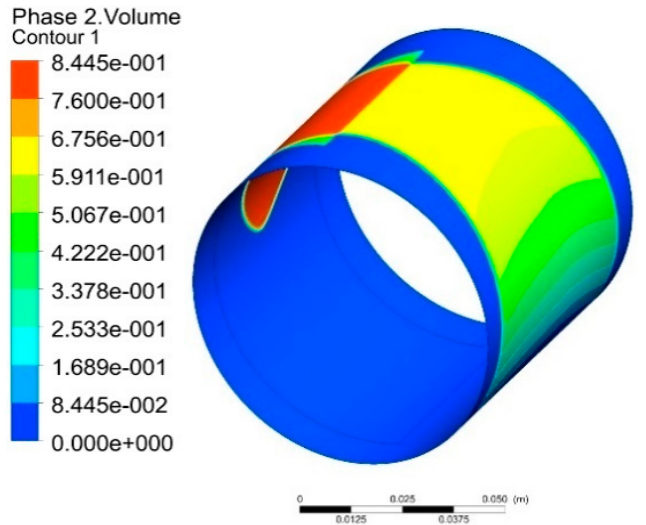

(b)

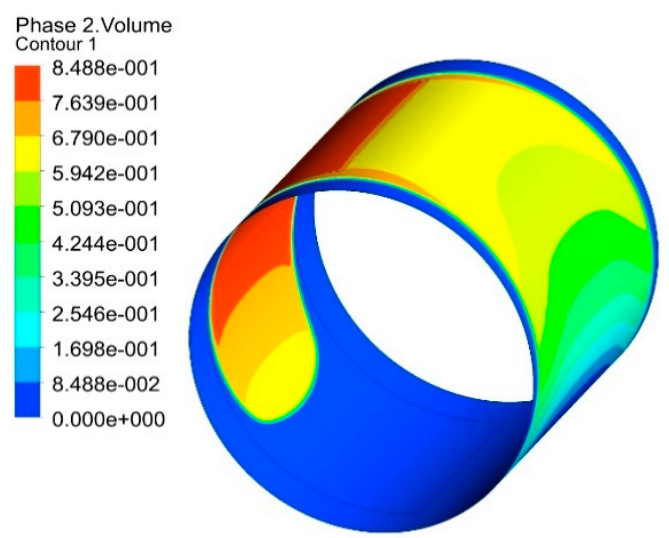

(d)

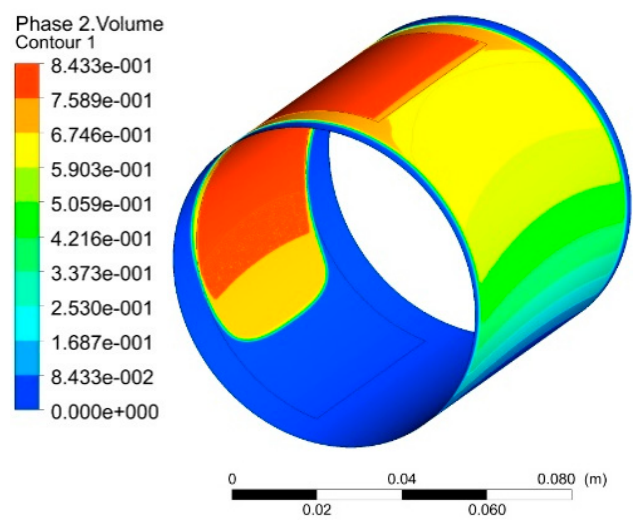

(e)

Figure 16. Contour of vapor volume fraction of the heterogeneous slip/no-slip bearing for various rotational velocity: (a) $n=100 ;$ (b) $n=500 ;$ (c) $n=1000 ;(\mathbf{d}) n=3000 ;(\mathbf{e}) n=5000$.

Figure 17 shows the characteristics of the load-carrying capacity for the heterogeneous slip/no-slip bearing under different rotational speeds. To note, the load-carrying capacity is defined as the integration of the hydrodynamic pressure over the contacting surface. Furthermore, load-carrying capacity is often considered as the main indicator of the tribological performance of the bearing. From Figure 17, it is clearly found that increasing the journal rotational speed results in an increase-then-decrease in the load-carrying capacity. It indicates that there is an optimal value of the rotational speed concerning the load-carrying capacity. As shown in Figure 17, at the shaft rotational speed of $3000 \mathrm{rpm}$, the heterogeneous slip/no-slip bearing has the best performance in terms of the load-carrying capacity. This is as expected because, based on Figure 13, for the bearing with $n=3000 \mathrm{rpm}$ 
the pressure profile has a wide pressure zone but with quite a high peak. These combined features lead to the highest load-carrying capacity. Besides, as illustrated in Figure 16d the cavitation area with a high value of vapor volume fraction for the case of the bearing with $n=3000 \mathrm{rpm}$ seems smaller than that with $n=5000 \mathrm{rpm}$. This leads to the destruction of fluid flow continuity and is also the reason why the load-carrying capacity of the bearing reduces when the operation condition with $n=5000 \mathrm{rpm}$ is chosen. It is interesting to note that when the higher shaft rotation speed is employed, the viscosity may reduce due to the increased average temperature. As reflected in Equations (4) and (5), the viscosity is a function of temperature. At some spots, in particular, at the high-temperature zone, viscosity can reach the lowest value. This phenomenon, which is often called the viscositywedge, has a strong effect on the load generation of the bearing, as explained by Meng and Khonsari [33].

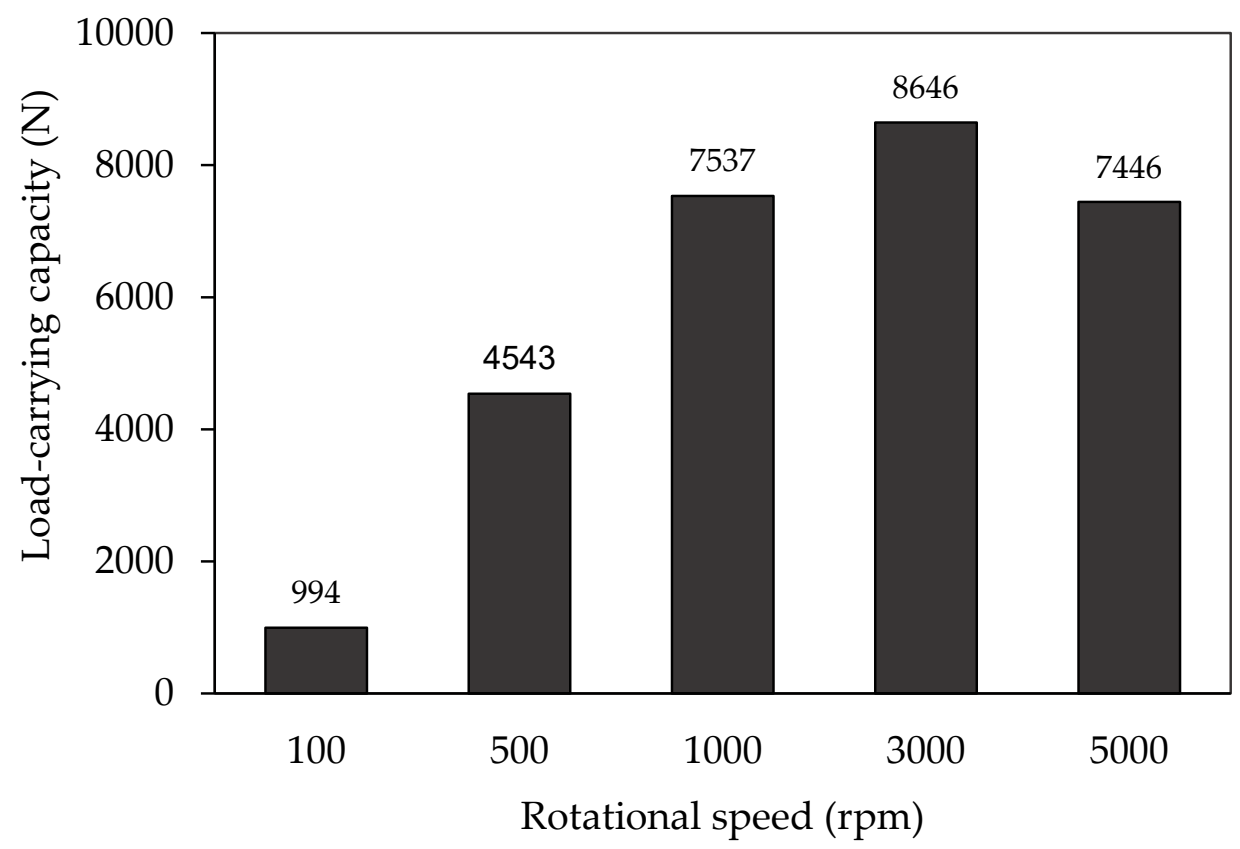

Figure 17. Load-carrying capacity of the heterogeneous slip/no-slip bearing for different rotational velocity $n$. All results are evaluated at $z / L=0.5$.

Figure 18 gives the variation of stationary wall temperature with different shaft rotational speed $n$. It can be clearly seen that increasing the shaft rotational speed $n$ results in a decreased temperature profile distribution. For lower $n(n=100$ and $500 \mathrm{rpm}$ in this case), no significant change in temperature is obtained. In other words, Figure 18 indicates that, when the rotational speed $n$ is higher than $1000 \mathrm{rpm}$, the temperature behaviour of the heterogeneous slip/no-slip is sensitive to the shaft rotational speed. For example, when the $n$ of $500 \mathrm{rpm}$ is increased by a factor of 10 , a ten-fold increase in the average temperature is achieved. This is as expected because more drag exists at the journal when the $n$ is increased.

It should be noted that, as the effect of boundary slip on journal bearing is very complex specifically in the heterogeneous slip/no-slip pattern, the present CFD model makes some hypotheses for simplification, for example, the constant slip length. Therefore, future studies should aim at exploring other numerical models featuring not-constant slip length at several external loadings in the presence of slip bearing and considering elastic mechanical deformation. In addition, experiments are needed for investigating the correlation between cavitation phenomena and thermal behaviour at the application of the heterogeneous slip/no-slip journal bearing. 


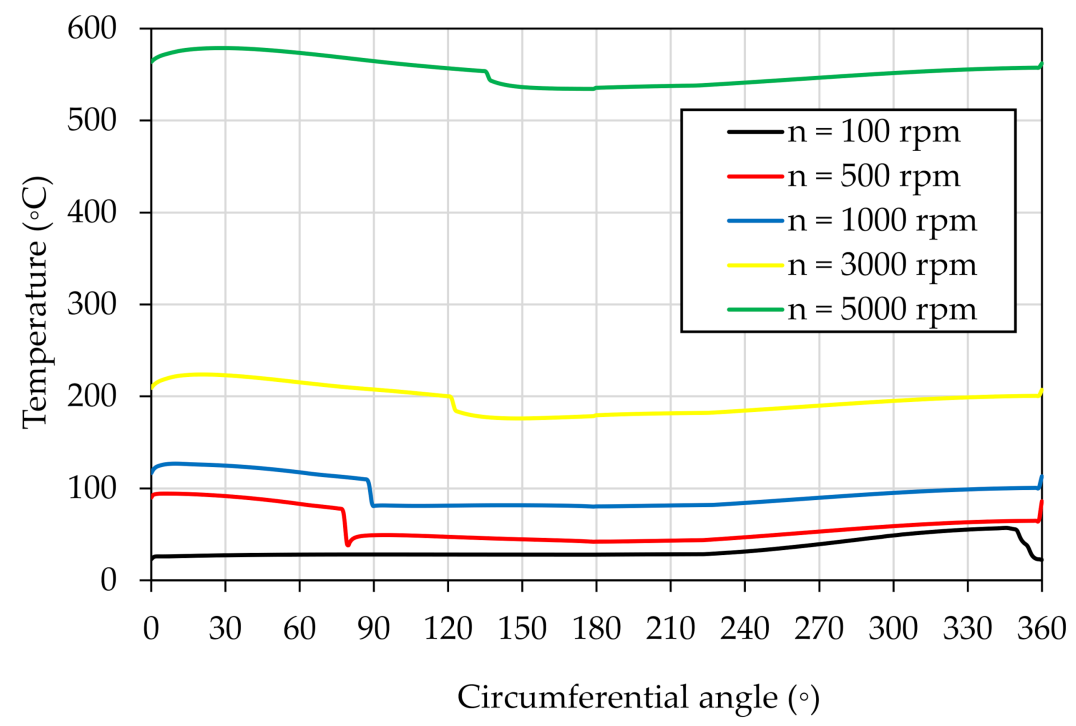

Figure 18. Temperature profile of the heterogeneous slip/no-slip bearing for different rotational velocity $n$. All results are evaluated at $z / L=0.5$.

\section{Conclusions}

The present work provides an in-depth analysis of the thermo-hydro-dynamic behaviour of heterogeneous slip/no-slip journal bearings, wherein essential performance parameters such as hydrodynamic pressure, vapor volume fraction, temperature, and load-carrying capacity are explored. The computational fluid dynamics (CFD) approach, including the multiphase "mixture" cavitation model, allows the change of phase to be fully explored. The effects of shaft rotational speed and the potential benefits of the use of heterogeneous slip/no-slip pattern are discussed. Based on the results and discussion mentioned earlier, these conclusions can be drawn:

1. The shaft rotational speed has a strong effect on bearing performance. Load-carrying capacity exhibits a nearly linear increase with shaft rotational speed up to a certain optimal value. The corresponding optimum shaft rotational speed for the maximum load-carrying capacity of the heterogeneous slip/no-slip pattern is $3000 \mathrm{rpm}$.

2. The performance parameters of heterogeneous slip/no-slip bearing under THD conditions are better, compared to the conventional bearing. The enhancement of the bearing performances consists of increased load-carrying capacity (up to 100\%) and reduced maximum temperature (up to $25 \%$ ).

3. Based on the multiphase "mixture" cavitation model adopted here, the simulations of the flow from the inlet boundary can accurately catch the phase change of the lubricant and the hydrodynamic characteristics of the heterogeneous slip/no-slip journal bearing. The heterogeneous slip/no-slip pattern has induced cavitation phenomena.

The present numerical results open up another approach, i.e., experiment to explore further the correlation between the cavitation phenomena and the presence of the slip under thermal effect. For future work, a further experiment could help to assess the thermal behaviour under different slip patterns, aimed at achieving the design of an efficient geometrical heterogeneous slip/no-slip pattern.

Author Contributions: Conceptualization, funding acquisition, writing-review \& editing, investigation, M.T.; Data curation, software, W.C.; Project administration, methodology, P.P.; Original draft preparation, visualization, resources, M.F.A.; Supervision, formal analysis, J.J. All authors have read and agreed to the published version of the manuscript.

Funding: This research is fully funded by "Penelitian Dasar" Grant, No. 225-74/UN7.6.1/PP/2020. 
Institutional Review Board Statement: Not applicable.

Informed Consent Statement: Not applicable.

Data Availability Statement: The data presented in this study are available on request from the corresponding author.

Acknowledgments: The authors fully acknowledged Directorate of Research and Community Service of Ministry of Research, Technology (DRPM-KEMENRISTEK), and Institute for Research and Community Services (LPPM), Diponegoro University for the approved fund which makes this important research viable and effective.

Conflicts of Interest: The authors declare no conflict of interest.

\section{Abbreviations}

$b$

c

$C_{p}$

$C_{p v}$

$D_{j}$

e

$F_{\text {cond }}$

$F_{\text {evap }}$

$h_{\text {max }}$

$h_{\text {min }}$

$L_{b}$

$L_{S}$

$L_{\theta}$

$n$

$\mathrm{O}_{b}$

$\mathrm{O}_{j}$

$p$

$p_{v}$

$p_{b l}$

$R_{b}$

$R_{b l}$

$R_{j}$

$R e_{c}$

$R e_{r}$

$T$

$u_{S}$

$v$

W

$W_{S}$

$\alpha_{\text {nuc }}$

$\alpha_{v}$

$\varepsilon$

$\lambda$

$\lambda_{v}$

$\mu$

$\mu_{v}$

$\tau_{c r}$

$\rho$

$\sigma$

$\rho_{v}$

$\varphi$

$\theta$ slip length: $\mathrm{mm}$

radial clearance, $\mathrm{mm}$

liquid specific heat capacity, J/kg.K

vapor specific heat capacity, J/kg.K

journal diameter, $\mathrm{mm}$

eccentricity distance, $\mathrm{mm}$

condensation coefficient

evaporation coefficient

maximum film thickness, $\mathrm{mm}$

minimum film thickness, $\mathrm{mm}$

bearing length (in $z$-direction), $\mathrm{mm}$

circumferential length of slip zone, $\mathrm{mm}$

circumferential length of bearing, $\mathrm{mm}$

rotational speed, rpm

bearing center, $\mathrm{mm}$

journal center, $\mathrm{mm}$

liquid hydrodynamic pressure, $\mathrm{Pa}$

vapor saturation pressure, $\mathrm{Pa}$

bubble pressure, $\mathrm{Pa}$

bearing radius, $\mathrm{mm}$

bubble radius, $\mathrm{mm}$

journal radius, $\mathrm{mm}$

critical Reynolds number

real critical number

temperature, $\mathrm{K}$

slip velocity, $\mathrm{m} / \mathrm{s}$

kinematic viscosity, cSt

load-carrying capacity, $\mathrm{N}$

width of slip zone, $\mathrm{mm}$

nucleation site volume fraction

vapor volume fraction

eccentricity ratio

liquid thermal conductivity, $\mathrm{W} / \mathrm{m} . \mathrm{K}$

vapor thermal conductivity, $\mathrm{W} / \mathrm{m} . \mathrm{K}$

liquid dynamic viscosity, Pa.s

vapor dynamic viscosity, Pa.s

critical shear stress, $\mathrm{Pa}$

liquid density, $\mathrm{kg} / \mathrm{m}^{3}$

liquid surface tension coefficient, $\mathrm{N} / \mathrm{m}$

vapor density, $\mathrm{kg} / \mathrm{m}^{3}$

attitude angle, deg

circumferential angle, deg 


\section{References}

1. Pit, R.; Hervet, H.; Leger, L. Direct experimental evidence of slip in hexadecane: Solid interfaces. Phys. Rev. Lett. 2000, 85, 980-983. [CrossRef]

2. Baudry, J.; Charlaix, E. Experimental evidence for a large slip effect at a Non-wetting fluid-solid interface. Langmuir 2001, 17, 5232-5236. [CrossRef]

3. Zhu, Y.; Granick, S. Limits of the hydrodynamic no-slip boundary condition. Phys. Rev. Lett. 2002, 88, 106102. [CrossRef]

4. Tretheway, D.C.; Meinhart, C.D. Apparent fluid slip at hydrophobic microchannel walls. Phys. Fluids 2002, 14, L9. [CrossRef]

5. Choi, C.H.; Westin, K.J.A.; Breuer, K.S. Apparent slip flows in hydrophilic and hydrophobic micro-channels. Phys. Fluids 2003, 15, 2897-2902. [CrossRef]

6. Cottin-Bizonne, C.; Cross, B.; Steinberger, A.; Charlaix, E. Boundary slip on smooth hydrophobic surfaces: Intrinsic effects and possible artefacts. Phys. Rev. Lett. 2005, 94, 056102. [CrossRef]

7. Kalin, M.; Polajnar, M. The effect of wetting and surface energy on the friction and slip in oil-lubricated contacts. Tribol. Lett. 2013, 52, 185-194. [CrossRef]

8. Fortier, A.E.; Salant, R.F. Numerical analysis of a journal bearing with a heterogeneous slip/no-slip surface. ASME J. Tribol. 2005, 127, 820-825. [CrossRef]

9. Kalavathi, G.K.; Dinesh, P.A.; Gururajan, K. Influence of roughness on porous finite journal bearing with heterogeneous slip/no-slip surface. Tribol. Int. 2016, 102, 174-181. [CrossRef]

10. Rao, T.V.V.L.N. Theoretical prediction of journal bearing stability characteristics based on the extent of the slip region on the bearing surface. Tribol. Trans. 2009, 52, 750-758. [CrossRef]

11. Bhattacharya, A.; Dutt, J.K.; Pandey, R.K. Influence of hydrodynamic journal bearings with multiple slip zones on rotordynamic behavior. J. Tribol. 2017, 139, 061701. [CrossRef]

12. Zhang, H.; Hua, M.; Dong, G.N.; Zhang, D.Y.; Chin, K.S. Boundary slip surface design for high speed water lubricated journal bearings. Tribol. Int. 2014, 79, 32-41. [CrossRef]

13. Wu, C. Performance of hydrodynamic lubrication journal bearing with a slippage surface. Ind. Lubr. Tribol. 2008, 60, 293-298. [CrossRef]

14. Ma, G.J.; Wu, C.W.; Zhou, P. Influence of wall slip on the dynamic properties of a rotor-bearing system. Tribol. Trans. 2008, 51, 204-212. [CrossRef]

15. Rao, T.V.V.L.N.; Rani, A.M.A.; Nagarajan, T.; Hashim, F.M. Analysis of slider and journal bearing using partially textured slip surface. Tribol. Int. 2012, 56, 121-128. [CrossRef]

16. Wang, L.L.; Lu, C.H.; Wang, M.; Fu, W.X. The numerical analysis of the radial sleeve bearing with combined surface slip. Tribol. Int. 2012, 47, 100-104. [CrossRef]

17. Cui, S.; Zhang, C.; Fillon, M.; Gu, L. Optimization performance of plain journal bearings with partial wall slip. Tribol. Int. 2020, 145, 106137. [CrossRef]

18. Lin, Q.; Wei, Z.; Zhang, Y.; Wang, N. Effects of the slip surface on the tribological performances of high-speed hybrid journal bearings. Proc. Ins. Mech. Eng. Part J J. Eng. Tribol. 2016, 230, 1149-1156. [CrossRef]

19. Aurelian, F.; Patrick, M.; Mohamed, H. Wall slip effects in (elasto) hydrodynamic journal bearings. Tribol. Int. 2011, 44, 868-877. [CrossRef]

20. Lin, Q.; Wei, Z.; Wang, N.; Chen, W. Effect of large-area texture/slip surface on journal bearing considering cavitation. Ind. Lubr. Tribol. 2015, 67, 216-226. [CrossRef]

21. Susilowati, S.; Tauviqirrahman, M.; Jamari, J.; Bayuseno, A.P. Numerical investigation of the combined effects of slip and texture on tribological performance of bearing. Tribol. Mater. Surf. Interfaces 2016, 10, 86-89. [CrossRef]

22. Rao, T.V.V.L.N.; Rani, A.M.A.; Nagarajan, T.; Hashim, F.M. Analysis of micropolar and power law fluid-lubricated slider and journal bearing with partial slip-partial slip texture configuration. Tribol. Trans. 2016, 59, 896-910. [CrossRef]

23. Rao, T.V.V.L.N.; Rani, A.M.A.; Mohamed, N.M.; Ya, H.H.; Awang, M.; Hashim, F.M. Static and stability analysis of partial slip texture multi-lobe journal bearings. Proc. Ins. Mech. Eng. Part J J. Eng. Tribol. 2019, 234, 567-587. [CrossRef]

24. Rao, T.V.V.L.N.; Rani, A.M.A.; Mohamed, N.M.; Ya, H.H.; Awang, M.; Hashim, F.M. Analysis of magnetohydrodynamic partial slip laser bump texture slider and journal bearing. Proc. Ins. Mech. Eng. Part J J. Eng. Tribol. 2019, 233, 1921-1938. [CrossRef]

25. Ausas, R.; Ragot, P.; Leiva, J.; Jai, M.; Bayada, G.; Buscaglia, G.C. The impact of the cavitation model in the analysis of microtextured lubricated journal bearings. J. Tribol. 2007, 129, 868-875. [CrossRef]

26. Sun, D.C.; Brewe, D.E. A high speed photography study of cavitation in a dynamically loaded journal bearing. J. Tribol. Trans. ASME 1990, 113, 287-294. [CrossRef]

27. Sun, M.; Zhang, Z. Experimental study of the film distribution of statically and dynamically loaded cylinder journal bearing. $J$. Shanghai Univ. 1997, 3, 500-507.

28. Fang, C.; Sun, M.; Wang, X. Experimental investigation of dynamically loaded journal bearing with panoramic view of transient oil film. Lubr. Eng. 2007, 32, 54-58.

29. Kasolang, S.; Ahmad, M.A. Preliminary study of pressure profile in hydrodynamic lubrication journal bearing. Procedia Eng. 2012, 41, 1743-1749. [CrossRef]

30. Dhande, D.Y.; Pande, D.W. Multiphase flow analysis of hydrodynamic journal bearing using CFD coupled Fluid Structure Interaction considering cavitation. J. King Saud Univ. Eng. Sci. 2018, 30, 345-354. [CrossRef] 
31. Sun, D.; Li, S.; Fei, C.; Ai, Y.; Liem, R.P. Investigation of the effect of cavitation and journal whirl on static and dynamic characteristics of journal bearing. J. Mech. Sci. Tech. 2019, 33, 77-86. [CrossRef]

32. Chen, Y.; Sun, Y.; He, Q.; Feng, J. Elastohydrodynamic behavior analysis of journal bearing using fluid-structure interaction considering cavitation. Arab. J. Sci. Eng. 2019, 44, 1305-1320. [CrossRef]

33. Meng, X.; Khonsari, M.M. Viscosity wedge effect of dimpled surfaces considering cavitation effect. Tribol. Int. 2018, 122, 58-66. [CrossRef]

34. Cui, J.; Kaneta, M.; Yang, P.; Yang, P. The relation between thermal wedge and thermal boundary conditions for the load-carrying capacity of a rectangular pad and a slider with parallel gaps. J. Tribol. 2016, 138, 024502. [CrossRef]

35. Li, M.; Zheng, S.; Ying, G.; Li, Q. Development and validation of the 3D temperature field simulation for the tilting pad journal bearings. Comput. Therm. Sci. 2017, 9, 151-163. [CrossRef]

36. Spikes, H.A. The half-wetted bearing: Part 1: Extended Reynolds equation. Proc. Ins. Mech. Eng. Part J J. Eng. Tribol. 2003, 217, 1-14. [CrossRef]

37. Neto, C.; Evans, D.R.; Bonaccurso, E. Boundary slip in Newtonian liquids: A review of experimental studies. Rep. Prog. Phys. 2005, 68, 2859. [CrossRef]

38. Tauviqirrahman, M.; Ismail, R.; Jamari, J.; Schipper, D.J. A study of surface texturing and boundary slip on improving the load support of lubricated parallel sliding contacts. Acta Mech. 2013, 224, 365-381. [CrossRef]

39. Choo, J.H.; Glovnea, R.P.; Forrest, A.K.; Spikes, H.A. A low friction bearing based on liquid slip at the wall. ASME J. Tribol. 2007, 129, 611-620. [CrossRef]

40. Wu, C.W.; Ma, G.J.; Zhou, P. Low friction and high load support capacity of slider bearing with a mixed slip surface. ASME J. Tribol. 2006, 128, 904-907. [CrossRef]

41. ANSYS Fluent: User Manual, version 16.0; ANSYS Inc.: Canonsburg, PA, USA, 2017.

42. Zwart, P.; Gerber, A.G.; Belamri, T. A two-phase flow model for predicting cavitation dynamic. In Proceedings of the Fifth International Conference on Multiphase Flow, Yokohama, Japan, 30 May-4 June 2004.

43. Cao, D.; He, G.; Pan, H. Comparative investigation among three cavitation models for simulating cavitating venturi. J. Northwestern Polytech. Univ. 2013, 31, 596-601.

44. Li, Q.; Zhang, S.; Wang, Y.; Xu, W.W.; Wang, Z. Investigations of the three-dimensional temperature field of journal bearings considering conjugate heat transfer and cavitation. Ind. Lubr. Tribol. 2019, 71, 109-118. [CrossRef]

45. Muchammad, M.; Tauviqirrahman, M.; Jamari, J.; Schipper, D.J. An analytical approach on the tribological behaviour of pocketed slider bearings with boundary slip including cavitation. Lubr. Sci. 2017, 29, 133-152. [CrossRef] 